\title{
Experimental Research on Application of Kinetic Model to Predict Shelf-life of Military Instant Rice
}

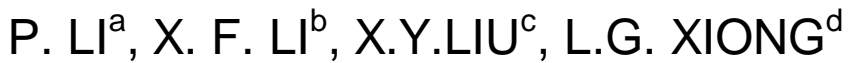 \\ Zhongshan Torch Polytechnic, Zhongshan Guangdong 528436, PR China

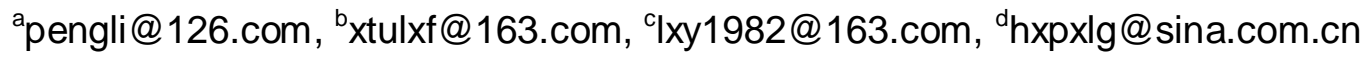

Keywords: Shelf Life, Accelerated Test, Instant Rice, Food Package.

\begin{abstract}
On the basis of accelerated test of food shelf life theory, the changes of acid \& peroxide value of military instant rice packaged by PET/AL/PA/PE coextruded film at different storage temperature were studied. The kinetics models of shelf life were obtained at corresponding temperature so as to predict the shelf life of instant rice. The study can be easily applied to predict food shelf life and package design of instant food at different storage temperature.
\end{abstract}

\section{Introduction}

Military food is an important component of logistics system in modern military for its particularity use, the package requirements of military food is far more strict than civil food, usually require saving 2 years in various special environment. As the main field food of PLA, instant rice's shelf life cannot reach the requirements at present, a certain period of packaging storage will cause deterioration and rancidity and produce unpleasant smell. The reason is mainly because the fat happens very complex oxidative degradation in the storage period. These problems seriously affect the instant rice's flavor and nutrition and cannot meet the requirements of combat readiness. These problems call for a immediate solution.

Food shelf life means the time span in which food can maintain its quality and consumption safety from production, packaging to sales process. Shelf life is usually determined by experiments, but many food can be stored for a long time after packing, so how to reduce experimental period and cost are the difficult points. In view of these, researchers proposed an accelerated test method to predict food shelf life (ASLT), its principle was to quantize the influence of environmental factors such as temperature, humidity, air pressure and light using kinetic reaction principle of food packaging system, raise the environmental serious degree to accelerate the deterioration of food. Because the factors cause deterioration can be quantized and the degree of the acceleration can also be calculated, so shelf life of food packaging in normal environment can be predict in a relative short period.

Foreign countries attached great importance to shelf life studies, according to the HACCP system, the United States and some other countries established the related regulations and standards[1]; Milena Sinigaglia, Maria R. Corbo[2] established a shelf life model of ready-to-eat coconut. Fritsch and Gale[3] evaluated the shelf life of corn and wheat in different storage temperatures. Domestic LIU Xiaodan etc. [4] took the sword bean as research object, estimated its shelf life in different temperature through Wechsler Analysis. ZHANG Lei [5] built regression equations to calculate the shelf life of paper salty fried peeling peanuts through accelerated oxidation experiments; ZHANG Ronghui[6] discussed the hydrological changing law of egg rolls under the condition of constant temperature and humidity using kinetic method, and predicted its shelf life under a low temperature, the result was good. In our country, researches in this field are in its infancy, relevant laws and regulations, standards have not been established. Researches of military food shelf life have not been published in public literatures, so it has great significance to research the military food's shelf life.

In this paper, the acid and peroxide value was chosen as the main factors, a kinetic model of military instant rice was built through accelerated experiment and the shelf life of military instant rice was predicted out. 


\section{Basic Theory of Accelerated Experiment}

\section{Evaluation Indexs and Detection Principle of Instant Rice's Quality}

Spontaneous reaction between lipid compounds and oxygen belongs to chain reaction of free radical. Same as all chain reactions, the course can be divided to three phases: triggering reaction, namely the formation of free radicals; free radicals transfer, namely a kind of free radical transfer to another kind of free radical; terminating reaction, namely two free radicals generate to a stable product. The formula of lipid compounds oxidation reaction is given by Eq. 1 .

triggering reaction:

free radicals transfer:

$$
\begin{gathered}
\mathrm{ROOH} \longrightarrow \mathrm{ROO}+\mathrm{H} \cdot \\
\mathrm{ROOH} \longrightarrow \mathrm{RO}+\mathrm{OH} \cdot \\
2 \mathrm{ROOH} \longrightarrow \mathrm{RO}+\mathrm{H} 2 \mathrm{O}+\mathrm{ROO} .
\end{gathered}
$$

$$
\begin{gathered}
\mathrm{R} \cdot+\mathrm{O} 2 \longrightarrow \mathrm{ROO} \cdot \\
\mathrm{ROO}+\mathrm{R}^{\prime} \mathrm{H} \longrightarrow \mathrm{ROOH}+\mathrm{R}^{\prime} .
\end{gathered}
$$

terminating reaction:

$$
\begin{gathered}
\mathrm{ROO}+\mathrm{R}^{\prime} \mathrm{OO} \cdot \longrightarrow \mathrm{ROOR}^{\prime}+\mathrm{O}^{2} \\
\mathrm{RO} \cdot+\mathrm{R}^{\prime} \longrightarrow \mathrm{ROR}^{\prime}
\end{gathered}
$$

Where R·, H·, RO·, ROO refer to free radicals; $\mathrm{ROOH}$ refers to unstable hydroperoxide, when reaches a certain density, it begins to break down into low molecular secondary product of alcohol, aldehyde and acid. These products will produce a smelly rancid flavor, reduce the quality of the food.

As the main factors of shelf life evaluation- "acid value" and "peroxide value", their detection method is as follows.

First, extract crude fat by Soxhlet Extraction Method, weigh dry samples, move it into cylinder-shaped paper filter, put cylinder-shaped paper filter into the extraction cylinder, connect to receiving bottle which has been dried to a constant weight, add water from the top of condenser pipe of extractor to $2 / 3$ of the extractor, heat in the water bath, make diethyl ether continuously be reflux extracted. Extraction should takes 8 hours and $2 \sim 3$ grams of crude fat can be extracted.

Acid value and peroxide value can be measured according to the method in national standard GB/T5009.37-2003. The method is as follows.

Acid value: take $3.00 \sim 5.00 \mathrm{~g}$ samples accurately in conical flask, add 50ml neutral mixture of diethyl ether and ethanol (1:1), shake it make oil dissolved, if necessary, put it in hot water to promote its dissolution. Cold it to room temperature, join $2 \sim 3$ phenolphthalein drops, titrating it with standard hydroxide potassium titration solution $(0.05 \mathrm{~mol} / \mathrm{L})$ to light red which will not fade in 0.5 min, then calculate hydroxide potassium consumption per gram of crude fat by Eq. 2 .

$$
X_{1}=\frac{V_{1} \times c_{1} \times 56.11}{m_{1}}
$$

Where X1—acid value of samples; V1—consumption volume of standard hydroxide potassium titration solution, $\mathrm{mL} ; \mathrm{cl}$ - density of standard hydroxide potassium titration solution, $\mathrm{mol} / \mathrm{L} ; \mathrm{ml} \longrightarrow$ mass of samples, g.

Peroxide value: take $2.00 \sim 3.00 \mathrm{~g}$ samples accurately in bottle with $250 \mathrm{~m} 1$ iodine, add $30 \mathrm{~m} 1$ mixture of chloroform and glacial acetic acid (2:3, V/V), make samples completely dissolved. Add $1.00 \mathrm{ml}$ saturated iodide potassium solution, closing the bottle cap and gently shake the bottle for 0.5 min, then place the bottle in dark for $3 \mathrm{~min}$. Add $100 \mathrm{ml}$ water, shake well, immediately titrate it with standard thiosulfate solution $(0.002 \mathrm{~mol} / \mathrm{L})$ to light yellow, add $1 \mathrm{ml}$ starch indicating liquid, continue to titrate it until blue disappeared. Calculate the amounts of peroxide, expressed as $\mathrm{X} \%$ which means the total amounts of peroxide contained in $100 \mathrm{~g}$ fat by Eq. 3 .

$$
X_{2}=\frac{\left(V_{2}-V_{3}\right) \times c_{2} \times 0.1269}{m_{2}} \times 100
$$


Where X2_-peroxide value of samples, g/100g; V2—consumption volume of standard thiosulfate titration solution, $\mathrm{mL} ; \mathrm{V} 3$ —reagent blank consumption volume of standard thiosulfate titration solution, $\mathrm{mL} ; \mathrm{c} 2$ — density of standard thiosulfate titration solution, $\mathrm{mol} / \mathrm{L} ; \mathrm{m} 2$ — mass of samples, g.

\section{Shelf Life Prediction Kinetic Model}

Most food's quality loss can be measured by loss of expected quality (such as nutrient or characteristic flavor) or production of unexpected quality(such as odor or fade)[8], given by Eq. 4 .

$$
F(A)=k t
$$

where $F(A)$ refers to food quality function; $k$ is reaction rate constant; $t$ is food storage time.

Different reaction levers refer to different function expression are shown in Table 1.

Tab. 1 Food Quality Function to Different Reaction Level

\begin{tabular}{|c|c|c|c|}
\hline reaction level & 0 & 1 & $\mathrm{n}(\mathrm{n}=2,3, \ldots \ldots)$ \\
\hline$F(A)$ & $A-A_{0}$ & $\ln A / A_{0}$ & $1 /(n-1)\left(A_{0}^{1-n}-A^{1-n}\right)$ \\
\hline
\end{tabular}

For example, lipid oxidation corresponds to reaction level $1^{[3]}$, the quality function is given by Eq. 5.

$$
\ln A / A_{0}=k t \text {, i.e. } A=A_{0} e^{k t}
$$

Where $A$ refers to food quality; $A_{0}$ refers to initial food quality, $k$ is reaction rate const; $t$ is food storage time.

As shown in Eq.(4), to a certain degree of spoilage, reaction rate constant had inverse ratio to the time that food reach a certain extent of quality loss, this pattern will continue until quality changes to unacceptable at time $t_{\mathrm{s}}$, named shelf life which can be expressed as Eq. 6 .

$$
\ln t_{s}=b T+a
$$

Where $t_{\mathrm{s}}$ refers to shelf life; $\mathrm{T}$ refers to temperature $\left({ }^{\circ} \mathrm{C}\right)$; $\mathrm{a}$ and $\mathrm{b}$ are const.

\section{Accelerated Experiment Scheme}

\section{Experimental Material}

Experimental subject: newly produced instant rice provided by Beijing military equipment institute of the general logistics department, sealed in iron drum in refrigerator for experiment.

Packaging material: PET/AL/PA/PE $(120 \mu \mathrm{m})$ compsite fism provided by Guangzhou Fu Xiang packing co., LTD.

Sample preparation: put $50 \mathrm{~g}$ instant rice into a $20 \mathrm{~cm} \times 16 \mathrm{~cm}$ PET/AL/PA/PE composite fism bag, then vacuum seal it for experiment.

\section{Index and Frequency of Measurement}

Index: acid value and peroxide value.

Frequency: For $65^{\circ} \mathrm{C}$ storaged sample, 5 days a time; For $55^{\circ} \mathrm{C}$ storaged sample, 10 days a time; For $45^{\circ} \mathrm{C}$ storaged sample, 25 days a time.

\section{Main Instrument and Equipment}

Vacuum packaging machine GBB-B Guangzhou BiaoJi Packaging Equipment CO., LTD, constant temperature humidity chamber 101-2S Wuxi Blodar Laboratory Equipment CO., LTD, electrothermal blowing dry box 101A Shanghai Experimental Instrument Factory, analytical balance(sensitivity weight $0.0001 \mathrm{~g}$ ) Shanghai Balance Instrument Factory, soxhlet extractor 
Shanghai YueJin Medical Equipment Factory, thermostat water bath HH-S Jiangsu Jintan City HengFeng Instrument Equipment CO., LTD.

\section{Experiment Method and Procedures}

Place samples in constant temperature and humidity chamber where $\mathrm{RH}=50 \%$, temperature respectively are $65^{\circ} \mathrm{C}, 55^{\circ} \mathrm{C}$ and $45^{\circ} \mathrm{C}$. Do the test according to method in chapter 2.1 , test should be done according to the standard requirements that require 12 hours at room temperature for stability before test.

\section{Shelf Life Prediction Kinetic Model}

Kinetic model of instant rice acid value (AV) change and peroxide value (POV) change in storage process

Instant rice's change curve of acid value as shown in Fig. 1 to Fig.3. Instant rice's change curve of peroxide value as shown in Fig. 4 to Fig.6.

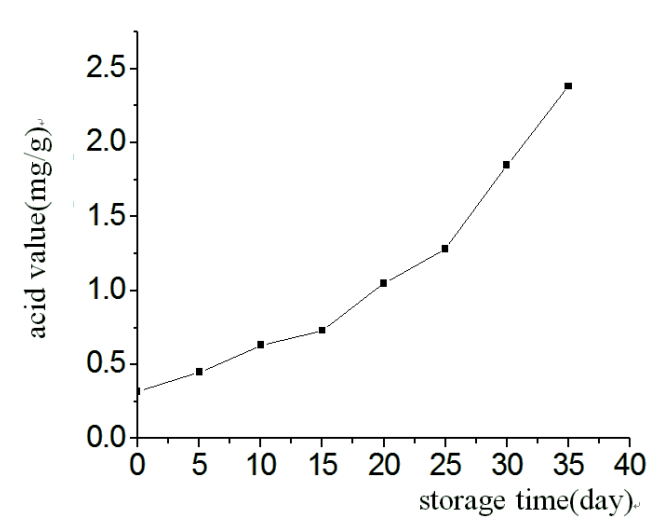

Fig. 1 Acid Value VS. Time $\left(65^{\circ} \mathrm{C}\right)$

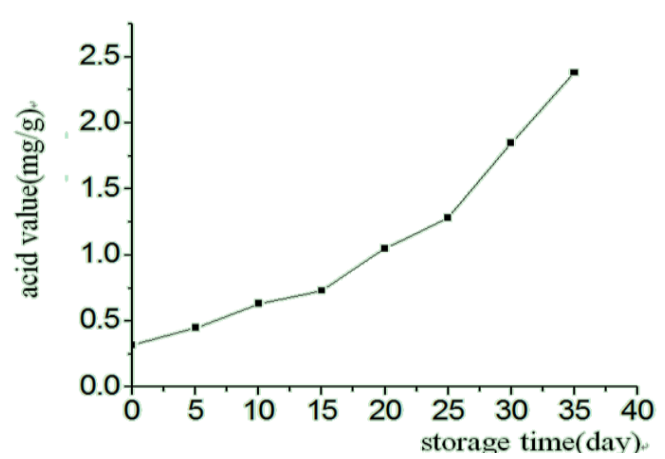

Fig.3 Acid Value VS. Time $\left(45^{\circ} \mathrm{C}\right)$

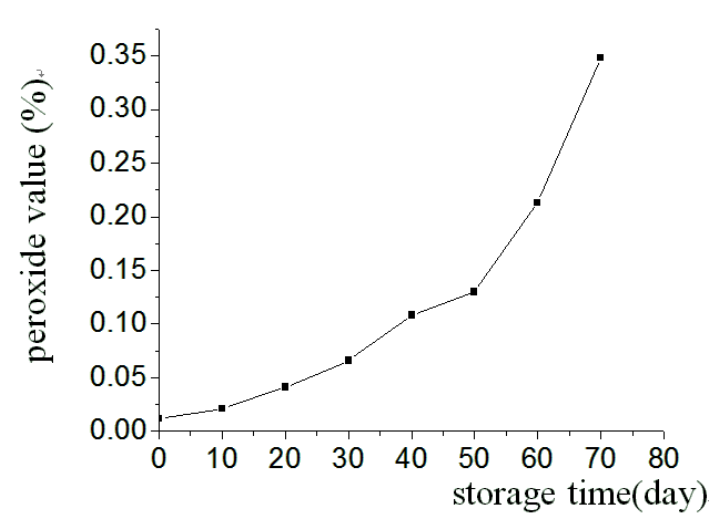

Fig.5 Peroxide Value VS. Time $\left(55^{\circ} \mathrm{C}\right)$

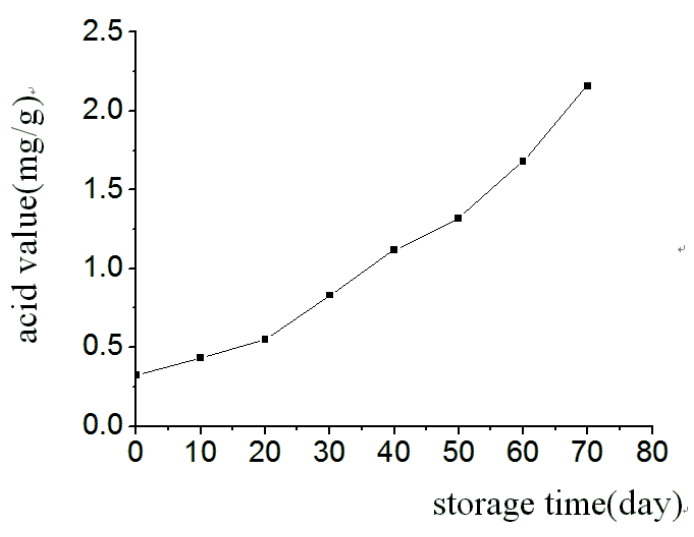

Fig. 2 Acid Value VS. Time $\left(55^{\circ} \mathrm{C}\right)$

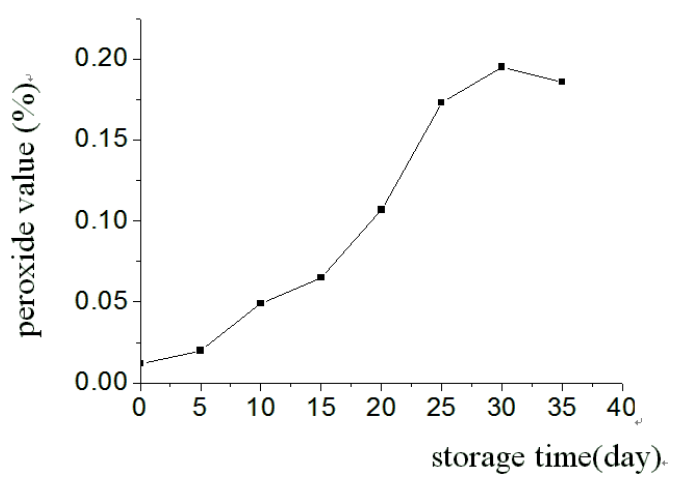

Fig.4 Peroxide Value VS. Time $\left(65^{\circ} \mathrm{C}\right)$

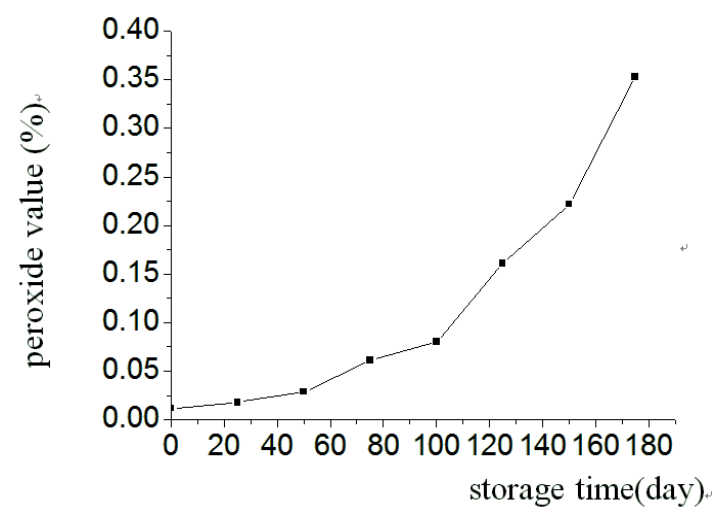

Fig. 6 Peroxide Value VS. Time $\left(45^{\circ} \mathrm{C}\right)$ 
As shown in Fig. 1 to Fig.3, along with growth of the storage time, acid value increased gradually. And the higher storage temperature was, the rate of increase of acid value was bigger. According to theory mentioned in chapter 2.2, acid value change kinetic model can be expressed as Eq. (5). Through regression analysis of experimental data, when temperature are $45^{\circ} \mathrm{C} 、 55^{\circ} \mathrm{C} 、 65^{\circ} \mathrm{C}$, the kinetic modal of acid value change are respectively given by Eq. 7 .

$$
\begin{aligned}
& A=0.3472 e^{0.0115 t} \\
& A=0.3680 e^{0.0254 t} \\
& A=0.3298 e^{0.0565 t}
\end{aligned}
$$

Where $\mathrm{A}$ is the acid value, $\mathrm{t}$ is the storage time.

The correlation coefficients of three temperature regression equation were both greater than 0.95 , showed that the regression equation had very high fitting precision. As shown in Eq. (7), along with the increases of storage temperature, acid value change rate increased, the experiment had been effectively accelerated.

As shown Fig. 4 to Fig.6, along with growth of the storage time, peroxide value increased gradually. But in Fig. 4, when storage time came to 30 days, peroxide value decreased a little, that was because peroxides began to decompose and the decomposition velocity was greater than production velocity, so proper revision should be induced in.

Peroxide value change kinetic model of instant rice also can be given as Eq. 8 .

$$
P=P_{0} e^{k_{p} t}
$$

Where $P$ is the peroxide value; $P_{0}$ is the initial peroxide value; $k_{p}$ is the change velocity of peroxide value; $t$ is the storage time(day).

By regression analysis of experimental data, when temperature were $45^{\circ} \mathrm{C} 、 55^{\circ} \mathrm{C}$ and $65^{\circ} \mathrm{C}$, the kinetic modal of peroxide value change was respectively given by Eq. 9 .

$$
\begin{aligned}
& P=0.01469 e^{0.0182 t} \\
& P=0.01599 e^{0.0438 t} \\
& P=0.01293 e^{0.0829 t}
\end{aligned}
$$

The correlation coefficients of three temperature regression equation were both greater than 0.95 , shows that the regression equation had very high fitting precision. As shown in Eq. (7), along with the increases of storage temperature, acid value change rate increased, the experiment had been effectively accelerated.

\section{Shelf Life Calculation}

According to relevant researches and standards [9], shelf life end point of instant rice can be defined as acid value $\leq 1.8 \mathrm{mg} / \mathrm{g}$, peroxide value $\leq 0.25 \%$ (both must be met). So experimental shelf life can be obtained from experimental data at different temperature; At the same time, substitute acid value and peroxide value in Eq. (7) and (9), shelf life of vacuum packing instant rice at different temperature can be calculated respectively, as shown in Table 2.

Tab. 2 Experimental Value and Calculating Value of Shelf Life at Different Temperature

\begin{tabular}{c|c|c}
\hline \multirow{2}{*}{$\begin{array}{c}\text { Storage conditions } \\
\left({ }^{\circ} \mathrm{C}\right)\end{array}$} & \multicolumn{2}{|c}{ Shelf life(day) } \\
\cline { 2 - 3 } & Experimental value & Calculating value \\
\hline 45 & 152 & 150 \\
\hline 55 & 67 & 68 \\
\hline 65 & 30 & 30.5 \\
\hline
\end{tabular}

As shown in Table 2, the calculating values and experimental values of shelf life are consistent 
with each other, showed that the kinetic model was of high accuracy.

From table 2, the relationship between logarithm of shelf life of instant rice $\left(\ln t_{s}\right)$ and storage temperature ( $T$ ) can be concluded as shown in Fig. 7. From Fig. 7, we can see that the relationship was linear as shown as Eq. 10 by a linear regression analysis.

$$
\ln t_{s}=-0.08045 T+8.61715
$$

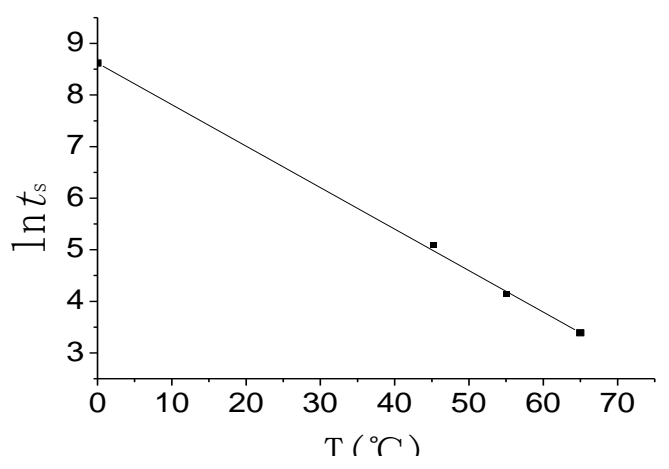

Fig.7 Relationship between Shelf Life and Storage Temperature

Shelf life of instant food in other temperature can be predicted by Eq. (10), such as shelf life is 739 days when $25^{\circ} \mathrm{C}$.

For the temperature changing with seasons, we can use average temperature to estimate the shelf life.

The above method only suits for PET/AL/PA/PE bag packaged instant rice and each batch of instant rice's initial acid value and initial peroxide value are required.

\section{Summary}

Based on basic theory and experimental method of food shelf life accelerated test, chose acid value and peroxide value of military instant rice as main factors for shelf life, the changing rule of acid value and peroxide value of military instant rice packaged by PET/AL/PA/PE material at $45{ }^{\circ} \mathrm{C}, 55^{\circ} \mathrm{C}$ and $65{ }^{\circ} \mathrm{C}$ was measured respectively by elevating temperature. Results show that experimental results and theoretical analysis results were in good consistence. Through the experiment, it was known that acid value and peroxide value of instant rice changing with time can be simulated by exponential function accurately, logarithmic value of shelf life and storage temperature were in linear relationship. The work of this paper provided a reliable theoretical basis and experimental method for design or predicting shelf life of snack food packaged in different temperature.

\section{References}

[1]Meet, Pultry Products, and Egg Products Inspection Acts, America, 2000.

[2]M. Sinigaglia and M. R. Corbo: International Journal of Food Science and Technology Vol.38(2003), p.156.

[3]C. W. Fritsch and J. A. Gale: 1996. J. Amer. Oil Chem. Soc. Vol.54(1996), p.225.

[4]X.D.Liu and J.Xie: Science and Technology of Food Industry Vol. 7(2006) p. 169.

[5]L.Zhang and X.Q.Xu: Packaging Engineering Vol. 4(1998), p. 264.

[6]R.G.Zhang, R.G.Yin and K.J. Xiao: Food Research and Development Vol.10(2001),p.93.

[7]H.B.Zhi and Y.H. Han: China Packaging Industry Vol. 11(2005), p.72.

[8]Z.Wang, S.Y.Xu and B. Jiang: Food Chemistry (China light industry press, Beijing 2003).

[9]DB22/T1086-2005,Q/SLD.04-2005. Relevant standards for convenient rice and porridge class products. 